\title{
CORRUPCIÓN Y CLEPTOCRACIA
}

\section{CORRUPTION AND CLEPTOCRACIA}

Luis Lamas Puccio

* Socio Fundador del Estudio Lamas Puccio \& Abogados Asociados

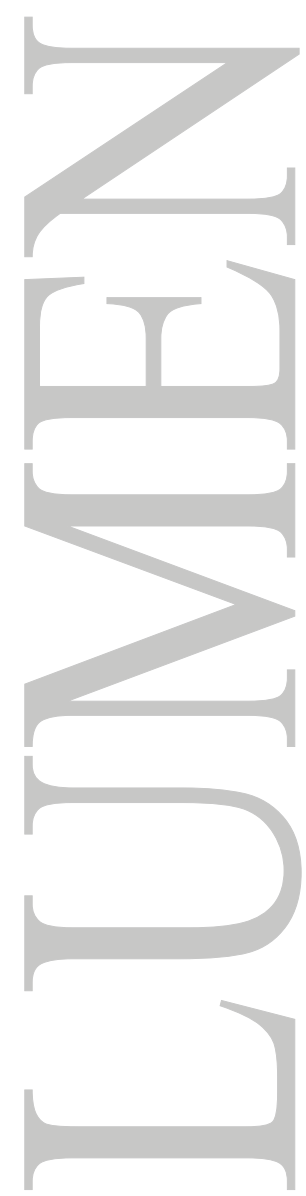




\title{
CORRUPCIÓN Y CLEPTOCRACIA
}

\author{
CORRUPTION AND CLEPTOCRACIA
}

Luis Lamas Puccio

\section{RESUMEN:}

Hacer una introducción sintetizada del problema de la corrupción y sus relaciones con la cleptocracia, en un mundo cada vez más interrelacionado y globalizado, en el que prima la digitalización de las relaciones interpersonales, implica en varios sentidos tratar de resumir o mejor dicho articular, en un solo texto literario toda una gran variedad de dificultades indistintas y contrapuestas, relacionadas con un problema de particular actualidad y de mucha vigencia.

\section{PALABRAS CLAVES:}

Corrupción, cleptocracia, dificultades, necesidad,

\section{ABSTRACT:}

Making a synthesized introduction to the problem of corruption and its relations with kleptocracy, in an increasingly interrelated and globalized world, in which the digitization of interpersonal relationships prevails, implies in several senses trying to summarize or rather articulate, in a single literary text a great variety of indistinct and conflicting difficulties, related to a particularly topical and current problem.

\section{KEY WORDS:}

Corruption, kleptocracy, difficulties, necessity

\section{INTRODUCCIÓN}

La situación actual de la corrupción, aunque puede haber variado en sus formas y modalidades, como fenómeno sigue siendo el mismo desde las épocas más remotas, aunque bajo distintos matices. Lo que puede haber cambiado es su fisonomía o sus formas, pero en la base sigue siendo lo mismo: una lucha constante y permanente, entre quienes piensan que el ser humano se debe a su colectividad y que ella se encuentra por encima de todo, y los que conceden prioridad a sus apetitos personales sobre los derechos de los demás, incluso a costa del desmedro social de grandes sectores poblacionales.

Refiero que articular el análisis de la corrupción, desde distintas perspectivas, implica una labor compleja y nada sencilla, en tanto que su finalidad más importante no es otra cosa que poner en evidencia y develar que bajo el manejo tergiversado y grandilocuente del discurso político, denominado de "lucha contra la corrupción", se esconde, amañadamente, una serie de parámetros y aseveraciones artificiosas y tergiversadas que lo que persiguen no es otra cosa que tratar, por todos los medios, de disimular o esconder los verdaderos rostros de la corrupción.

La priorización para investigar la corrupción como tema de importancia y actualidad, en el contexto de las relaciones internacionales y la globalización; surge de la necesidad imperiosa de ubicar sus causas, razones y desenvolvimiento actual, en la trama intermedia, entre las actividades económicas o empresariales y las esferas políticas, donde se maneja el poder en la sombra.

Se trata de una visión diferente, sobre la etiología de la corrupción a gran escala, que involucra la gobernabilidad, el sistema económico, el flujo de capitales y los partidos políticos, germinada a raíz de la presencia constante de reiterativos casos de "gran corrupción", en los que aparecen 
involucradas las altas esferas del poder con la participación de toda una gama de personajes que desarrollan labores políticas, económicas y partidarias. Esto pone en entredicho el rol y la función de la democracia representativa y pluralista, sobre la que se afirma eufemísticamente como la expresión máxima de la gobernabilidad y el respeto a los derechos ciudadanos.

En el presente caso, me refiero a una orientación heterogénea, y, a la vez disímil, aunque unificada en un solo concepto llamado cleptocracia, y sus estrechas relaciones con la corrupción, ya no solo a nivel local sino fundamentalmente en un contexto global. Mientras que en su propio entorno fluye una frondosa e impenetrable zona gris que pasa desapercibida, en la que se sitúan estratégicamente las reglas del mercado en una economía neoliberal triunfante, el flujo o recirculación incontrolable de capitales. Todo esto de la mano con un poder económico inconmensurable, centrado en el poder de las grandes empresas trasnacionales, la tergiversación de las funciones de los partidos políticos, la corrupción misma, la cínica legitimación de capitales, en un mundo que pareciera que tiene dos caras opuestas; la cleptocracia como una de las máximas expresiones de la corrupción actual, la proliferación de los paraísos financieros en todos los continentes, una meritocracia indolente, un clientelismo modernizado, adecuado a los requerimientos actuales, y las elites políticas y financiadas que pugnan por acaparar un poder político como no se había visto antes.

Implica la existencia de una pugna por controlar el poder, en su máxima expresión, en un régimen global inflexible y totalmente copado, que ha logrado desarticular de manera progresiva y sutil las débiles protecciones que todavía existían hace algunos años. Éstas, en alguna medida, resguardaban los mercados nacionales, regulando el intercambio de bienes y servicios, los movimientos sospechosos de capitales; una actividad empresarial en muchos casos indolente, una responsabilidad funcional muy venida a menos, y una fiscalización internacional mediocre y limitada por los intereses políticos, en el marco de una la lucha permanente, frontal y poco escrupulosa por capturar un poder económico como forma de gobernar.

El triunfo de las reglas del mercado sobre las economías de los estados y la corrupción al más alto nivel en los gobiernos, coludidos con el poder económico, las mafias criminales y el poder político en la esfera donde se manejan las más importantes decisiones, han convertido en una ilusión aquellos mecanismos de representación de las grandes mayorías, referidos a la democracia como sistema, que en algún momento sustentaron la transparencia en el manejo de la política y la ética en materia de gobernabilidad.

Sobre el particular, es importante reflexionar refiriéndonos a aquellos componentes como la delincuencia económica, el manejo doloso de las finanzas, la protección trasnacional de los mercados, las crisis financieras, las operaciones con información privilegiada, la manipulación de los mercados, la progresiva e inducida transferencia de competencias, la ausencia de autoridades nacionales e internacionales en materia de regulación, la existencia de ordenamientos jurídicos adrede desfasados, los turbios negocios sobre las deudas soberanas, y la presencia de grandes inversores internacionales, como una nueva expresión de la corrupción en un mundo globalizado.

Me refiero a la denominada opacidad, que no es otra cosa que una gran ventaja operativa para los grupos de poder, en muchos casos carentes de escrúpulos, relacionados con la «corrupción de cuello blanco» que gestionan los mercados financieros de la actualidad, los mismos que resultan más atractivos y eficaces cuando prima de por medio una mayor libertad de acción frente a las restricciones públicas ${ }^{1}$.

Hernandez, J. (2012) "El casino que gobierna el mundo: mañas y trampas del capitalismo financiero". Ediciones Le monde diplomatique. "El Diplo» Capital intelectual de la presente edición: Capital Intelectual. S.A., Primera edición argentina, p. 48. 
Se alterna una nueva dimensión sobre la forma como ahora opera la corrupción, en un mundo interdependiente, a partir de un ámbito de intercomunicación social, distinto al espacio físico que hasta hace algunas décadas marcaba las pautas en materia de control de la corrupción, fiscalización y control social. A partir de un nuevo enfoque criminológico con especial interés con respecto a los presupuestos sobre las actividades cotidianas que no ameritaban mayor esmero, surge ahora el denominado ciberespacio que ofrece especiales y atractivas condiciones a la corrupción, en particular, y a la criminalidad en general. Aparece un ámbito distinto de oportunidades más eficaces e indetectables en materia de corrupción y aseguramiento de su éxito casi absoluto respecto a la impunidad y aseguramiento, muy distantes a las estrategias preventivas del pasado que estaban enfocadas en el espacio físico. "Por medio de la abstracción teórica y la conexión de los elementos del crimen (la corrupción palabra del autor), surge las particularidades de un nuevo "lugar" para la comisión delictiva, conocido como el ciberespacio" ${ }^{2}$.

A ello, se suma una desregulación paradigmática de los mercados internos, como la causa principal de muchos males nacionales; la desaparición del control sobre los sistemas bancarios; la disminución constante de la presión fiscal; la mundialización y fragmentación de los espacios sociales; la irracionalidad de las estructuras de producción; el papel fundamental de los medios de comunicación que informan o desinforman, de acuerdo a sus intereses, como algunos de los factores más importantes que han hecho invisibles, para el común denominador de los ciudadanos, la corrupción y los ilícitos cometidos por los poderosos que rara vez llegan a los tribunales de justicia.

Desde hace varias décadas se vive una aguda crisis moral y ética que suele tener vinculaciones con el manejo de la política y la economía, la que se trasluce en distintos casos de corrupción. Probablemente, la corrupción de los últimos años ha ido adaptándose a distintos procesos y manifestaciones referidas a la pequeña y a la gran corrupción. Los mercados financieros y los partidos políticos se han visto involucrados en casos graves de corrupción, bajo distintas modalidades, algunas calificadas en la legislación de la materia como delitos, otras como simples faltas administrativas, y, posiblemente, las más graves han pasado desapercibidas para el legislador, poco interesado en generar leyes sobre la materia. Esto sucede desde la perspectiva doméstica o nacional como desde la internacional, que resulta cada vez más compleja y enrevesada. El mundo globalizado vive dificultades sistémicas. De colapsos más o menos definidos que involucran los sistemas financieros nacionales e internacionales, y por supuesto, un gran número de ciudadanos que han padecido de forma directa a indirecta una falta de transparencia y ética, en el correcto manejo de los recursos públicos, ausentes en muchos lugares, que son los que más los necesitan. El mercado financiero y la democracia viven una crisis de confianza, sobre todo en los países en donde las instituciones públicas de fiscalización y control que tienen una serie de falencias, y cuyo restablecimiento y credibilidad pasa por la recuperación de la confianza y la transparencia en el desempeño de la labor pública.

Hay una extendida apreciación acerca de la desproporcionalidad existente entre determinadas prácticas políticas relacionadas con el abuso del poder económico y la corrupción (cuando se las descubre), que, en muchos casos, o han pasado desapercibidas o las sanciones que se han impuesto han sido irrelevantes con la magnitud del daño ocasionado. Me refiero al proceso engorroso para la depuración de las conductas ilícitas y la imposición de las correspondientes sanciones, las mismas que encuentran grandes obstáculos, en la práctica, cuando son motivo de seguimiento o procesamiento, en tanto que muchas de ellas terminan impunes o con sanciones meramente administrativas. Suele señalarse que una justicia tardía no es justicia, y que es solo un proceso que cumple tan solo una formalidad o una creencia. Incluso, suele hablarse de intereses colectivos, vinculados no solo con el sistema partidario y el sistema político, sino con la misma democracia que frente a casos de esta naturaleza pierde credibilidad porque no funciona cuando

2 MIRÓ, F. (s.f) "La oportunidad criminal del ciberespacio. Aplicación y desarrollo de la teoría de las actividades cotidianas para la prevención del cibercrimen”. http://criminet.urg. es/recpc. 
se trata de los poderosos. Evidentemente, el menoscabo de la ética, en el manejo de la política y los negocios, tiene que ver mucho con el deterioro de una moral en sentido positivo, lo cual plantea condiciones propensas para que la corrupción coludida con el poder político y económico se afiance.

Se suma una ausencia manifiesta y clamorosa de una persecución penal rápida, eficaz y adecuada, frente a una amplia serie de conductas asociadas o corporativizadas ante lo que se denomina como una nueva dimensión de la corrupción, en gran parte frente al desinterés de los mismos estados y de los gobernantes para adecuarse a las nuevas circunstancias y desafíos. Todo ello como resultado de un mundo cada vez más globalizado, en el que la corrupción conforme se va desarrollando, paulatinamente, adquiere nuevos y complejos matices. Los mecanismos de distracción frente al colectivo humano, en un mundo global cada vez más interconectado con una tremenda capacidad de convencimiento y adoctrinamiento, juegan un papel importante y estratégico sobre el manejo de las noticias y la interpretación misma de los acontecimientos. Lo cual depende de los intereses que se encuentren de por medio, y si conviene o no ocultarlos o sobredimensionarlos; con mayor razón, si se trata de hechos o conductas no violentas, en el contexto de las relaciones económicas y de poder, que no tienen las características de los delitos atroces o comunes, y que por lo tanto no afectan lo cotidiano.

Me refiero a la conjunción de tres factores fundamentales que, aunque aparentemente diferentes o distantes en su análisis e interpretación individual, se desenvuelven en la realidad, bajo la misma línea: economía, corrupción y política. De acuerdo a lo expresado, la corrupción aparece enunciada en las conexiones existentes entre el clientelismo político, la dependencia mutua y el poder económico. Todo ello, bajo la creencia que preconiza que la ley resulta imparcial y es la máxima expresión de la justicia. El resultado no es otra cosa, que un neopatrimonialismo, a ultranza, como forma histórica del poder invisible que subyace y adquiere nuevas dimensiones o formas en la sociedad actual, dependiendo de cómo se quiera interpretar y qué es lo que se quiere ocultar.

La existencia de una continuidad política en la alternancia del poder, en el presente caso matizada por el debate, siempre tiene una sola razón de ser: no estar desvinculada del régimen político que gobierna. En lo que se refiere a las economías neoliberales, el sitio de ubicación del poder dependerá, en última instancia, del desarrollo de las fuerzas productivas, y, en especial, del refinamiento alcanzado por el modelo de acumulación de capital.

El abuso del poder, en el desarrollo de la política, forma parte del mismo ejercicio del poder que se encuentra dentro de una formación social y política determinada, y, por consiguiente, obedece a sus propios mecanismos. Por lo tanto, conformarse con una definición de abuso de poder y de la corrupción producida por la escogencia política o del sistema normativo (en el presente caso la ley), o, lo que es lo mismo, producida por el propio poder, no hace otra cosa que contribuir en mantener intacta la estructura de las relaciones de dominación que se ejercen bajo el esquema de la gobernabilidad y la democracia.

De hecho, la corrupción sigue siendo el problema más importante, que involucra a la gobernabilidad casi en su totalidad, y parecería no tener solución, a pesar de lo que constantemente se propone en materia legislativa y de las medidas que se implementan. El señalar acciones concretas contra la corrupción es la propuesta más importante que tiene que hacer todo aquel que aspira a hacer política en nuestro medio, y lograr expectativas electorales futuras. Sin embargo, la corrupción no solo no ha disminuido, sino que, al margen de seguir siendo el problema más sensible, cada partido político que llega a gobernar vuelve a develar facetas desconocidas e inéditas sobre cómo la corrupción operaba en las esferas del poder. 
Es cierto que la corrupción, en particular en el ejercicio del poder, las actividades económicas y la política partidaria, continúa siendo la cara más visible y representativa de un largo y complicado proceso histórico, en el que se superponen los intereses particulares, en desmedro de las mayorías, afectándonos a todos por igual. Los casos más recientes de corrupción, en las altas esferas del poder suscitan una inflexión en el análisis tradicional sobre las causas y los motivos de la corrupción en el Perú.

Los acontecimientos más recientes, develados en materia de corrupción y gobernabilidad en el ejercicio del poder, suscitados a lo largo de las tres últimas décadas, hacen evidente de que se trata de un problema penetrante y perspicaz que no puede ni debe ser abordado a través del discurso político, con declaraciones reiteradas, las buenas intenciones, y su recurrencia a la modificación de la ley penal.

El tema es que mientras subsistan las estructuras del poder, en los términos y condiciones como actualmente existen y operan, en el reconocido marco de la legalidad, cualquier intento de cambio, transformación o de reforma resultará siempre diluido y licuado por la poderosa sinergia de intereses que subyace entre el poder político y el económico. Se trata, en realidad, de una alianza de intereses que hace posible, por un lado, que se logre alcanzar el poder político en base al financiamiento de las campañas políticas, y por otro lado, que se consolide el poder económico enmascarado dentro de las políticas de estado; ésta ópera libremente en una economía caracterizada por el absoluto e irrestricto dominio del neoliberalismo a escala mundial, que no es otra cosa que la punta del iceberg de una desestructuración de la sociedad, con la correspondiente conmoción de la coherencia entre los espacios sociales, económicos y políticos.

De acuerdo a lo señalado, el enfoque que prevalece en nuestro trabajo asume como premisa en la comprensión de la corrupción, que la ética y la moral, a lo largo de la historia, han jugado un rol fundamental desde que los filósofos griegos y los que los continuaron en la brega hasta la actualidad, establecieron las bases sólidas e inmutables que con el paso de los siglos son irreversibles sobre lo que debe concebirse como una verdadera felicidad, la honra, el placer y el libre albedrío, en el entendido que enfrentamos un crepúsculo de la ética, en una sociedad postmoralista.

En ese sentido, juega un rol protagónico, en la comprensión cabal de la corrupción, el neoliberalismo como exaltación del materialismo como máxima expresión del logro individual, la desarticulación del Estado frente a la fortaleza necesaria para enfrentar una corrupción global; el fraccionamiento de la sociedad, desarticulada por el poder económico y la extraterritorialidad, ante un fenómeno que va más allá de las jurisdicciones nacionales impotentes para enfrentarlo y que abusa de la territorialidad. Juegan un papel fundamental, en este análisis, la cibercorrupción, la criminalidad en la política, la bancarización global, el flujo de capitales, el secretismo, la confidencialidad, la trasnacionalidad de la corrupción, el abuso de poder, la ética empresarial, y la manipulación de la corrupción, a través de la percepción.

La corrupción política juega un papel clave en el análisis de la misma corrupción como fenómeno global, en tanto que es materialmente imposible lograr una separación fáctica entre la tergiversación de los fines de la política, lo económico como preponderante, y el abuso de poder que está presente en todo fenómeno importante en materia de corrupción. Anomia, impunidad, mimetización, concientización, legalidad, manipulación, legalidad y gobernabilidad, son algunas de las nuevas características que involucran a la corrupción en los momentos actuales.

Visto de esta manera, la corrupción requiere copar el poder, hacer mal uso de la democracia para consolidarse, estructurarse y a la misma vez poder fortalecerse. De igual forma, juegan un rol estratégico el lobbismo, las poliarquías, la partidocracia, el clientelismo, el populismo, la continuidad en el poder, la anarquía y el desorden como una manera de copar el sistema de justicia, en aras de 
lograr la meta más importante, que no es otra cosa que la impunidad como la máxima expresión de la corrupción como fenómeno político y económico.

Con cara al futuro y frente a los nuevos acontecimientos que sacuden el planeta, el problema de la corrupción requiere ser afrontado no solo desde una óptica delictiva o normativa, sino desde una perspectiva unitaria, y a la vez distinta, para ubicarlo en el centro de la controversia, que es donde realmente corresponde; es decir, entre las actividades económicas y empresariales a nivel global y la política como eje de la democracia, en consideración a que los mercados y el comportamiento de las empresas, en un mundo cada vez más globalizado, aparecen tan importantes en igualdad de condiciones a la circulación de las elites políticas en su constante y permanente lucha por la autoridad y copar el poder.

En efecto, la perversidad del discurso contra la misma corrupción y la "lucha contra corrupción", como posible solución a un problema de contenido histórico, nos brinda determinadas reflexiones sobre los límites o alcances a los que ha llegado la degradación de la ética en la política, en el ejercicio de la democracia representativa y frente al abuso del poder económico. Me refiero a la manipulación de la información para mostrar, por un lado, determinadas facetas de la corrupción que suscita el escándalo, y del otro lado, ocultar otras actividades relacionadas también con la corrupción. Todo ello dependiendo de los intereses que se encuentren en juego, y que tan conveniente o inconveniente resulta "informar" o mejor dicho "desinformar" a la opinión pública, si lo que se persigue es que determinados actos de la propia corrupción pasen desapercibidos o sean entendidos de manera distinta.

Existe hoy en día un acuerdo bastante amplio sobre la gravedad de la crisis que estamos atravesando. Tal es así que múltiples análisis surgidos de los más diversos ámbitos sociales, políticos y académicos - incluso desde diferentes perspectivas ideológicas y políticas - destacan la profundidad y a la vez, la complejidad del fenómeno de la corrupción en el mundo actual. De esta forma, podría decirse que existe un consenso reciente a la hora de situar ciertos elementos estructurales que se encuentran en el entorno de la corrupción: criminalidad, pobreza, democracia, poder, política, ética y manejo de la información.

En ese sentido, para ubicar la real dimensión de la corrupción, en términos y condiciones de análisis, es fundamental asumir como cierto lo que relata en los mismos términos y condiciones Gonzalo Fernández Ortiz de Zárate:

El proyecto de la modernidad capitalista - que se entiende como el nexo asimétrico entre el universo filosófico de la modernidad y su sustrato ilustrado, por un lado, como el capitalismo como propuesta hegemónica y universalizable en lo económico, por el otro—, ha posicionado los parámetros fundamentales de este último como valores fuertes, relegando las señas de identidad ilustradas - ciudadanía, soberanía, igualdad, libertad, etc. - a simples valores débiles. Esto es, principios de segunda división, supeditados y redefinidos en función de los primeros, que sirven únicamente como recurso discursivo si no logran acomodarse a los considerados fuertes y que tienen valor, en la medida en que le son funcionales. La modernidad capitalista se define como un proyecto civilizatorio integral - económico, social, político y cultural - y con pretensiones de universalidad, donde el capitalismo ejerce como eje articulador, no necesariamente determinante en todos los aspectos, y valor del mismo (Quijano, 2014).

Se trata, por lo tanto, de una civilización que acentúa su carácter productivo y consumidor; que resalta el papel de la naturaleza como simple proveedora de bienes; que prima el mercado por encima de toda actividad social; que establece el lucro como motivador principal de la acción de las personas (Wilkinson, 2009) y que lleva en su origen la huella indeleble de la 
desigualdad, la ingobernabilidad, la insostenibilidad y la violencia. En ese sentido, la misma gestación de la modernidad capitalista parte de un proceso fundacional de acumulación originaria - que sentó las bases para su eclosión posterior durante la Revolución Industrial - que se sustenta sobre la conversión violenta de las clases subalternas en proletariado, a través del cercamiento, la privatización y la mercantilización: sobre la instauración de un nuevo orden heteropatriarcal [...].

Y son precisamente estas prácticas de desigualdad, ingobernabilidad, insostenibilidad y violencia intrínsecas al proyecto modernizador las que, en la fase actual de globalización neoliberal, se han ahondado y desboscado, en una lógica de evolución natural de los valores fuertes del proyecto civilizatorio. De esta manera el énfasis en el progreso individual, en la primacía del lucro y de la ganancia como premisa de bienestar, así como la democracia liberal - representativa como forma de organización política, han conducido a la modernidad capitalista a mostrar su verdadera identidad, más allá del relato teórico, a partir de un sistema de dominación múltiple (Valdés, 2009), que afecta a las grandes mayorías sociales y el conjunto del planeta.

En ese sentido, la modernidad capitalista se desarrolla en la práctica como una hidra en la que el capitalismo, inherentemente inestable, asimétrico y en permanente conflicto entre clases, se sostiene y se alía con otros sistemas de dominación para posibilitar su reproducción ${ }^{3}$.

La interrogante que surge sobre las causas que motivan la corrupción, nos hace pensar que no se trataría en exclusividad de un problema relacionado con la trasgresión de la ley y el orden, en los términos como siempre se enfoca y analiza la trasgresión social y otras actividades que se le relacionan. Existe consenso entre la doctrina y de parte de los especialistas al afirmar que la corrupción como fenómeno social y político afecta y deteriora por igual, las bases mismas sobre las que descansa la democracia y la gobernabilidad, como parte intrínseca del sistema de jefatura de las naciones y sobre la dirección que cada sociedad asume frente a la corrupción. Si las conductas en materia de corrupción se convierten en una práctica constante de intercambios de favores, dádivas y el provecho que se obtiene del mal ejercicio de la función pública, entonces la percepción y el convencimiento de los ciudadanos no hace otra cosa que suscitar perspicacia y desencanto en el entendimiento que no se trata de un problema propio de la corrupción, sino más orientado a la forma y manera como se está gobernando respecto a que en lugar de primar el interés de las mayorías, por el contrario se atiende a los beneficios de los grupos que ven en el propio control de la gobernabilidad el mejor medio de enriquecerse, siempre a costa de las expectativas y el engaño que sufren los ciudadanos cuando ven que la democracia es un sistema de gobierno que no funciona de acuerdo a los principios de igualdad y representatividad. Entonces, los ciudadanos sienten que el interés general es sustituido por el interés privado del funcionario de turno y quienes lo secundan, quien haciendo tabla rasa a la ley sustituye los principios democráticos por decisiones personales basadas en la habilidad para pagar, esconder y engañar ${ }^{4}$. En consecuencia, la confianza del ciudadano en las instituciones democráticas se pierde y la legitimidad del Estado aparece socavada, difuminándose así la base sobre la cual ha de asentarse el Estado democrático y de Derecho, propiciando el desprestigio no solo de los políticos o sus partidos sino del sistema democrático en su conjunto 5 .

3 Fernández, G. (2016) "Alternativas al poder corporativo: 20 propuestas para una agenda de transición en disputa con las empresas trasnacionales". Icaria - Antrazyt. Economía, Barcelona, pp. 30 y siguientes.

4 Rose - Ackerman, S (s.f) "The political Economy of Corruption", en ELLIOT, KIMBERLY A.: "Corruption and the global Economy". Mencionado por DEMELSA BENITO SÁNCHEZ, en "EI Delito de corrupción en las transacciones comerciales internacionales", p. 42.

5 Fabián, E. (2003) "La corrupción del agente público extranjero e internacional". Tirant lo Blanch, Valencia. p. 37. Mencionado por DEMELSA BENITO SÁNCHEZ, en "El Delito de corrupción en las transacciones comerciales internacionales". Ob. cit., p. 42. 
Cuando un ciudadano entrega un soborno a un funcionario para lograr algún tipo de favor o beneficio, implica un hecho cuestionable desde todo punto de vista, no solo porque se trastoca o porque se vulnera la relación entre persona civil y autoridad, sino porque se afecta los derechos de igualdad que es la base de la democracia. Si ello es así, más cuestionable aún es cuando, a través del ejercicio de la misma democracia se engaña o se hace mal uso de esta para beneficio de los que ejercen el gobierno y sus relaciones con el poder económico, a través de los partidos políticos bajo el esquema de lo que preconiza la democracia.

Me refiero al estudio prevaleciente que pone en el centro del análisis de la corrupción el mal ejercicio de la política frustrando las expectativas ciudadanas.

Se trata como menciona, Giulio Sapelli, de:

El enfoque prevaleciente en el análisis de la corrupción es el que pone a la dimensión política en el centro de la explicación de este problema.

Se trata de un reflejo del peso creciente asumido en los países por la dimensión que adquieren la regulación y el control de los mercados. La causa principal de esto es tanto el rol que el Estado ha desempeñado y continúa desempeñando de diversos modos para favorecer los procesos de crecimiento económico, como el peso que en los procesos democráticos (o bien autoritarios) de participación política han asumido los partidos políticos. Se ha superado así lo que en una época era el límite entre política y administración, llegando en algunos casos a la llamada "balcanización política" de esta última. La "balcanización política" del Estado consiste en la ocupación de la que es objeto por parte de los grupos de poder cuyos componentes ya no son fieles a los ideales del Estado como representante de la comunidad, sino más bien a los deseos de los líderes de estos grupos de poder.

No se trata, en efecto, de un problema nuevo: todas las sociedades organizadas han debido enfrentarlo y, según los modelos teóricos prevalecientes en cada momento, lo han sistematizado conceptualmente ${ }^{6}$.

Ha acontecido por lo general que los estudios sobre la corrupción no han enfrentado esta compleja realidad, ya que se han centrado casi siempre en los conflictos que surgen entre el ejercicio de la función pública, entendida como tal, y los fines de los particulares frente a la administración pública. La corrupción siempre ha aparecido en medio de estas dos esferas, es decir entre la función pública y la labor de los privados: de la separación que se verifica entre tales fines, nace la corrupción ${ }^{7}$.

Una vez más, Giulio Sapelli señala:

O bien, por otro lado, se detienen en el tema de la falta de autonomía entre la autoridad burocrática-estatal -que debería estar libre de las distorsiones y las heterogénesis de sus propios fines- y las autoridades de hecho que se producen gracias al poder acumulado por aquellos que operan los mercados. Para comprender los mecanismos de la corrupción, gran parte de los estudios que siguen este camino plantean la hipótesis de que los comportamientos sociales de los actores de esta se encuentran determinados por cálculos racionales, dirigidos a maximizar los beneficios monetarios. Estos últimos sostendrían la acción hasta el límite en el que los costos previstos (las sanciones penales) no superen las posibles ventajas ${ }^{8}$.

6 Sapelli, G. (1998). Cleptocracia. El ‘mecanismo único’ de la corrupción entre economía y política. Editorial Losada, Buenos Aires., pp. 17 y 18.

Ibid., p. 19.

Ibid., p. 19. 
Este estado de descomposición, en materia de corrupción, surge cuando los vínculos sociales, como secuela de las obligaciones político-jurídicas no satisfacen las necesidades para los cuales fueran creadas. Implica una ruptura como resultado no de hechos circunstanciales u ocasionales, sino más bien de actitudes continuas y homogéneas que se entrelazan unas con otras y hacen difícil diferenciar si en realidad nos encontramos frente a una patología individual que solo corresponde a un solo factor, o por el contrario de un problema que implica una coordinación entre factores. Esto es lo que ha sucedido en algunos países, cuando la corrupción y, más específicamente las ilegalidades económico- políticas se han convertidos en hechos tan visibles que han logrado convertirse en un fenómeno de grandes proporciones que afecta la cultura democrática, el sistema político y el mismo sistema económico.

Me refiero en forma específica a las causas y a la estructura de la corrupción como una variante significativa y a la vez decisiva de la ilegalidad y el abuso del poder en los términos y condiciones en el que se desenvuelven las relaciones económicas y políticas de una sociedad en particular.

Antes de referirse de manera puntual a la noción de cleptocracia es importante manifestar que la evolución del concepto de corrupción sobre el cual interactúan todas las acciones legales implica hasta la fecha -en una gran medida- recurrir en forma directa a la desviación como una de las premisas sobre las que se fundamenta el control. Las normas legales desempeñan un rol fundamental en el análisis de los hechos en razón a que en última instancia es "la ley" la que define qué conductas están permitidas y cuáles son las que están prohibidas y cuya materialización implica la aplicación de un castigo o una sanción de contenido penal. Siempre la sanción penal ha tenido mayor peso psicológico y político frente a las conductas que violentan el orden legal imperante. Me refiero a todas aquellas conductas "legalmente reprochables" que aparecen descritas en las leyes y los códigos penales, frente a las cuales el Estado tiene la prerrogativa, una vez agotado un proceso, de considerar que una persona es culpable o inocente.

La violación de las normas legales, sobre todo las que tienen un alto contenido punitivo o represivo que aparecen descritas en las leyes penales, tiene un papel característico en el tratamiento de la corrupción. Es en muchos casos lo que marca las pautas en el devenir y el control de la corrupción a mediano plazo. El tipo de orden normativo, respecto del cual la corrupción constituye una desviación o trasgresión (orden jurídico positivo, normas sociales, costumbres, moral y ética), ha sido y sigue siendo, en gran medida, la ruta o el eje motriz a través de la cual se define, se concibe o conceptualiza el problema de la corrupción en su esencia. Entre las que cabe destacar por su trascendencia la calificación del fenómeno como un acto de orden criminal. Y en el terreno propiamente procesal, la demostración o verificación de la culpabilidad de una persona que es investigada o acusada por un hecho de corrupción.

Sin embargo, no está tan claro que las definiciones propiamente "técnicas» y "funcionales" que circunscriben la posibilidad de calificar la corrupción como tal, al ejercicio de la función pública especializada, utilicen la legalidad o la ilegalidad positiva como orden normativo relevante y esclarecedor del tema. Gran parte de las construcciones conceptuales existentes o modernas giran en torno a una brecha o a una distancia (que en realidad es una relación de mutua referencia) entre legalidad o sistema normativo positivo y prácticas sociales, o bien como los llama Riesman, entre sistema mítico y código práctico, o entre lo escrito y lo no escrito, o entre legalidad y cultura, o entre una dimensión simbólica o relatada dependiendo de los intereses que estén en juego ${ }^{9}$. Las definiciones sobre delitos son ideológicas, en consideración a que en muchos casos contribuyen en mantener oculta una amplia esfera de dominación, la cual como en muchos casos son de corrupción. Encontramos conductas como tales que no están catalogadas, y, sin embargo, en el ejercicio de la práctica política conspiran contra la transparencia en el ejercicio de la labor pública, en el desarrollo, en el bienestar y, en especial, en el manejo de los recursos públicos.

9 Rabotnikof, N. (1999) Corrupción política: definiciones técnicas y sentidos sedimentados. Universidad Nacional Autónoma de México. 
Como lo venimos manifestando, supeditarse o mejor dicho conformarse a una definición de corrupción, producida por escogencia política (la ley), o lo que es lo mismo por la actitud selectiva que genera la norma legal, en determinados casos, contribuye en mantener intacta la estructura básica de las relaciones de dominación sobre la que se desenvuelve la corrupción, orientando la atención pública sobre un debate en materia de legalidad o ilegalidad. Es decir, mientras que un acto de corrupción no aparezca definido, fijado y sancionado en la ley como tal, pasará desapercibido para la opinión pública, al margen de que puede ser objeto de tergiversación y por consiguiente también de manipulación.

En efecto, se tiene la impresión de que si al analizar una transacción política se deja de lado o se minimiza como criterio la percepción de un beneficio económico individual o la apropiación de fondos públicos (criterios que sirven para definir los sobornos, las extorsiones, los fraudes y las malversaciones), o se los reemplaza de un modo un poco laxo por «beneficios políticos». Hay una zona en la que diferentes formatos de intercambio político y prácticas corruptas pueden llegar a confundirse conceptualmente.

De esa manera, se descubre un espectro oscuro de la corrupción que es donde se ubica la cleptocracia como resultado de una triangulación entre el poder económico, el poder político y las empresas que encuentran un espacio apropiado donde desenvolverse, sin mayores posibilidades de poder ejercer sobre ella algún tipo de control o fiscalización. Por ende, el poder político y social, y el poder económico como base, no son como en un primer momento se puede pensar entes aislados, como muchas veces se afirma en el análisis de los problemas sociales y políticos entidades aisladas y que no se relacionan unas con otras solo para temas coyunturales. Son parte de una estrategia para copar el poder abusando de las prerrogativas que ofrece la democracia. Hay entre todas ellas, una relación simbiótica o de dependencia mutua que, cuando se juntan, pasan a convertirse en un poder, si se quiere omnímodo y de capacidad casi total o limitada.

Si se trata de la corrupción y su presencia en el marco de la cleptocracia, los abusos de poder son formas de corrupción que implican generalmente, un abuso de poder político y viceversa. Los diferentes regímenes políticos, por otra parte, con sus variantes en las características del tipo de poder que los alimenta, van desde el poder oligárquico, al elitista e influyen en la ubicación de las ilegalidades en los diferentes elementos de la estructura lineal de las conductas posibles, dependiendo del refinamiento del sistema y del régimen considerado. Los abusos de poder pueden darse en cualquiera de los tres niveles en los que el poder se expresa: el poder político, el poder económico y el poder ideológico. Cualquiera de estos tres niveles ofrece la posibilidad de un tratamiento autónomo, siempre que no se pierda de vista la relación que existe entre los tres ${ }^{10}$.

Por lo tanto, las definiciones de ilegalismos, y por resultado de delito en materia de corrupción, tienen un alto contenido ideológico y político que es manejado por escogencia de la ley para esconder o develar intereses.

La cleptocracia como una modalidad importante de corrupción y poco desarrollada en algunos medios nacionales, supone, antes que nada, la institucionalización política de la misma corrupción en todas y cada de sus facetas, en las que se puede desenvolver un Estado, los partidos políticos, las empresas y el poder económico a nivel nacional y global. Esto se da tanto a nivel transversal, corporativo, concertado, como estructura piramidal e incluso con un sentido jerárquico y hasta geopolítico. Ello en razón a que no solo se trata del robo o sustracción sistemática de los recursos del Estado para beneficio de los malos gobernantes y en desmedro de los gobernados, sino del abuso del poder económico y político, en toda su amplitud para realizar actividades mostradas o encubiertas de corrupción en las altas esferas del poder. Como refiere, Giulio Sapelli:

10 Mantellini G., Pedro J., Aniyar, L. y Linares M. (agosto 1980) TEMA, III. "Delincuentes y abuso de poder: delitos y delincuentes fuera del alcance de la ley" p.43, VI Congreso De Las Naciones Unidas Sobre Prevención Del Delito Y Tratamiento Del Delincuente, llevado a cabo en Caracas, Venezuela. 
Esta discrasia emerge con dramatismo no solo cuando la vida social discurre con uniformidades "invisibles", sino cuando los vínculos sociales, sean de obligaciones político - jurídicas, sean de la moral, ahora aparecen rotos y trastocados: cuando la ruptura se da, no en forma ocasional y discontinua, sino más bien continua y homogénea, en una proliferación social en la que se puede perder de vista la diferencia existente entre patología y fisiología ${ }^{11}$.

Al respecto, se explica que la corrupción puede ser definida como un intercambio clandestino o encubierto entre dos "mercados", aparentemente cada uno con su propio fuero y hasta distantes en apariencia: por una parte, el "mercado político y/o administrativo", y por la otra parte, el "mercado económico y social". Este intercambio es oculto porque viola las normas públicas, legales y éticas, en tanto que sacrifica el interés general o colectivo en aras del interés particular o privado (ya sean individuales, corporativos o partidaristas). De esta manera, los actores públicos corruptos, al participar en este tipo de transacción, permiten que los actores privados accedan a los fondos $\mathrm{o}$ a las decisiones públicas de una manera privilegiada o favorecida que de otra manera no sería posible, con la finalidad de lograr u obtener beneficios materiales y económicos inmediatos. Implica una estrecha interacción entre lo público y privado en determinados sectores de la administración pública que no necesariamente aparecen sujetos a reglas que no son de cumplimiento obligatorio. Mientras más existan reglas precisas que encierran el arbitrio personal, existirá menos posibilidades de casos de corrupción por la estrechez de los espacios que tienen los funcionarios corruptos para poder actuar a su favor ${ }^{12}$.

Como lo manifestamos, afrontamos el fenómeno de la corrupción en los momentos actuales, en un mundo globalizado que, desde una perspectiva unitaria, interactiva, hegemónica, y a la vez sistémica, ubica la corrupción en el mismo contexto en el que se desarrolla la economía y envuelve a la política a través de la democracia y la partidocracia. Una patología social en la que el comportamiento del poder económico, en el entorno de la manipulación de los mercados, implica la entronización del poder económico con capacidad suficiente como para ejercer influencia e injerencia sobre la gobernabilidad y la democracia. Dicho de otra manera, estamos hablando de las causas y de la estructura de la corrupción como una variante de la ilegalidad político económica, en la que se interconecta la organización de la sociedad con las conductas practicadas por determinados actores, en una estrecha compenetración entre el sistema económico y sistema político, en la medida de poder alcanzar un weberiano criterio de objetividad ${ }^{13}$.

Este tipo de corrupción supone varios factores de distinta etiología, categoría y razonamiento; algunos ya mencionados a lo largo de la presente obra, entre los que destacan por su importancia no solo la misma corrupción como fenómeno autónomo y diferenciado, por lo menos en condiciones normativas, sino la inclusión de otros portentos como la partidocracia, el clientelismo, el nepotismo, el abuso del poder, la manipulación colectiva y el uso indiscriminado de todo tipo de beneficios y artimañas como consecuencia de la arbitrariedad de las propias prerrogativas que preconiza la ley, el sistema democrático y el derecho sobre las que descansa la igualdad entre los ciudadanos y sus relaciones con el Estado. Implica, en su esencia, distintos comportamientos desviados e ilegales, no por su esencia o etiología, sino por su propio convencimiento, en el entendido de que se trata de prácticas que no solo deben ser catalogadas como delictivas o criminales, sino que se desarrollan en un contexto de legalidad que las oculta - las hace pasar desapercibidas, aunque en su trasfondo afectan el orden democrático y la posibilidad de lograr una sociedad más cohesionada y pacífica en términos de convivencia y distribución de la riqueza.

11 Ibid., p. 12.

12 Mény, Y. (1996) "Política, corrupción y democracia”. En Política y Gobierno, Volumen III, Número 1. Primer semestre, p. 155.

13 Ibid. 
De esta manera, la misma legitimidad del Estado y su fidelidad al mismo (en el presente caso a la ley como la máxima expresión), aparecen a la vez subordinadas y a la misma vez violentadas, dado que la tendencia a la acción que se supone guiaría a los sujetos que se encuentra involucrados, en una "esfera de cultura cívica", sería solo instrumental y oportunista como herramientas para el logro de los fines que persiguen. De esa manera, se instaura una doble legitimidad; una doble moralidad; y una doble fidelidad (al Estado al hacerse uso de las atribuciones que le asisten al funcionario, y a favor de los intereses de los privados para el logro de ventajas).

Se refiere a un enfoque prevaleciente respecto al análisis y las causas que suscitan o motivan la corrupción desde una perspectiva más coherente poniéndose especial énfasis en su dimensión política, como el centro de la explicación del problema.

Cuando hablamos de cleptocracia, el fenómeno delincuencial de "cuello blanco" (white collar) corrupción - abuso de poder, cuyo marco excede el marco tradicional de la corrupción convencional, y que con todo rigor podemos circunscribir a la llamada "cifra dorada de la corrupción", es percibido adrede, de manera minimalista y manipulado para tales efectos. Tangencialmente secundado de manera subsidiaria a la legislación penal para lograr u optar por un control administrativo que no genera mayores consecuencias, entre otras razones, para quienes legislan y actúan con una función política, que sirve en el fondo más a los intereses de los grupos de poder o los partidos políticos que a la propia población. Se trata de mantener el propio estatus, el cual surge y se consolida de las relaciones de producción muy bien determinadas y controladas por el factor capital ${ }^{14}$.

\section{Como señala, Rabotnikof N.:}

Se trata de aquellas formas de intercambio político por las cuales se negocian bienes de distinto género, ubicados entre la economía y la política normal, y que en determinados casos se enmarcan dentro de la mejora de salarios, facilidades de crédito, acceso a obras sociales, estado versus política, consensos democráticos, detención del disenso, aplazamiento de sanciones, etc.), que en la práctica son formas de intercambio político que desde una concepción normativa acerca de la naturaleza originaria de la política no pocas veces son o han sido caracterizadas como prácticas corruptas out court. Es por ello, que algunos autores hacen el esfuerzo para distinguir, por ejemplo, entre "políticas públicas promocionales" y actos propios de corrupción (Malem, 1977) ${ }^{15}$.

En otras palabras, la legitimidad del Estado y su fidelidad al mismo como se hace de manifiesto cuando se afirma el acatamiento a la ley, estarían subordinada, y a la vez violada o violentada, por los mismos que ejercen la gobernabilidad en representación de toda la sociedad. Esto en razón a que la tendencia a la acción como característica fundamental sería solamente instrumental, aparente y oportunista o de fachada, en consideración a que lo que reluce en el trasfondo no es otra cosa que una "doble lealtad", una "doble moral", en donde lo que despunta es una actitud favorable que responde a los intereses de determinados particulares, que buscan mayores ventajas o beneficios que los que permite la ley, incluso, por un mayor plazo a lo permitido.

El problema central no es tanto la eliminación completa de las formas de relaciones personalistas para favorecer el funcionamiento de las relaciones sistémicas y en particular del mercado, sino más bien la creación de un mix de confianza a la relación personal e institucional con capacidad suficiente como para sustentar el desarrollo [...]. Se observa -ha escrito Mauro Magatti- que factores culturales institucionales concurren para determinar el equilibrio entre las diversas formas de relaciones fiduciarias. El factor decisivo para la definición del resultado final es el entramado de las condiciones históricas en las que se

14 Mayorca, J. (1977) "Criminalidad de la Burguesía”. Caracas p. 15.

15 Rabotnikof, N. (1999) "Corrupción política: definiciones técnicas y sentidos sedimentados". Ob. cit., p. 29. 
estructuran las relaciones de intercambio de mercado, y más particularmente el rol del Estado y las prácticas de relaciones sociales (Magatti, 1993, p. 14) ${ }^{16}$.

En efecto, ahora se presenta una forma de hacer política que nos hace recordar fórmulas de manipulación y presión que se empleaban en épocas pasadas, aunque potenciadas por los medios tecnológicos que ofrece la modernidad, en un escenario estrechamente interconectado en el que resulta preponderante el control del ciudadano que se organiza a través del ejercicio de la política.

Tenemos ahora, bajo una forma distinta, una nueva feudalidad que, en parte, reproduce la sustancia de la antigua. En esos tiempos, los señores congregaban a sus vasallos para hacer la guerra y, si obtenían victoria, los recompensaban con el botín. Hoy, los políticos y los líderes sindicales actúan del mismo modo y congregan a sus tropas para las elecciones, a los efectos de llevar a cabo actos de violencia contra sus adversarios y obtener de tal modo beneficios que los vencedores disfrutan (Pareto, 1964. pp. 277-278) ${ }^{17}$.

Como, señala, Giulio Sapelli, el entender a Pareto es fundamental para comprender la forma histórica concreta sobre la corrupción, y a la vez, en general sobre los distintos matices sobre los que se apoya la corrupción, sobre toda la política que es la que ha adquirido mayor auge y matices, a raíz de las transformaciones sociales y políticas que ha traído la globalización. Su razón principal reside en la posibilidad de que a través de su análisis podamos verificar la estrecha interconexión que existe entre las colusiones monopólicas y las comunidades cerradas sobre las que actúan las empresas, en el contexto de las luchas o contiendas políticas por el poder y el control de la gobernabilidad. Se trata de destruir la democracia haciendo uso de los partidos políticos, los que en muchos casos actúan sin encontrarse ajenos a las sinergias sobre las que se desenvuelven los mercados para alcanzar el poder, a través de la astucia, la corrupción, el engaño, e, incluso, la violencia cuando se hace necesaria como último recurso para imponerse ${ }^{18}$.

Expresemos, de acuerdo con Pareto, que no existen alternativas o posibilidades para superar las condiciones infranqueables que imperan en el mercado, caracterizadas por su uniformidad y homologación como para aplastar cualquier posibilidad o intento de rastrear comportamientos fraudulentos que se movilizan en el contexto del fraude y el engaño. Todo esto se deriva de la concepción de poder, como praxis que se articula a través de distintos instrumentos que las clases dominantes utilizan, con el uso de la fuerza y el mal uso de la política (clientela política). Ellas se articulan a través de los acuerdos de entendimientos subrepticios entre los gobiernos y los "especuladores" ("el rostro tácito del poder")" 19.

Por ejemplo, un gobierno proteccionista goza de la confianza y la colaboración de los industriales protegidos, sin necesidad de que se hagan acuerdos explícitos con todos, pudiendo muy bien hacerlo con los principales. De modo similar sucede con las obras públicas [...] el acuerdo con los grandes empresarios se convierte en regla. Hay luego medios más conocidos, menos trascendentales desde el punto de vista social, pero que son en cambio considerados más importantes, desde el punto de visto ético, y de los que forman parte ahora, los actos de corrupción política de electores, electos, gobernantes, periodistas, etc. Estos tienen antecedentes en los gobiernos absolutistas, con la corrupción de cortesanos, de favoritos, favoritas, de gobernantes, de generales, etc., los cuales, por cierto, no han desaparecido por completo. Tales medios fueron empleados en todos los tiempos, desde la antigua Atenas y la Roma republicana, y llegan hasta nuestros tiempos, pero ellos son precisamente la

16 Sapelli, G. (1998). “Cleptocracia. El 'mecanismo único’ de la corrupción entre economía y política”. Editorial Losada, Buenos Aires, p. 22.

17 Parteto, V. (1964) “Trattato di sociología generale”. Introducción de N. BOBBIO, Comunitá, Milán. Copiado de SAPELLI GIULIO. Ob. cit., p. 75.

18 Ibid. p. 76.

19 Ibid. p. 77. 
consecuencia de una clase que con astucia se impone para conducir un país. Es por eso por lo que las innumerables tentativas hechas para reprimir su uso han sido, y lo son hoy, vanas: se puede cortar cuantas veces se quiera la gramilla, pero ésta vuelve a crecer con más brío si queda intacta la raíz. Nuestras democracias, en Italia, en Francia, en Inglaterra, en los Estados Unidos, nos reconducen hoy, cada vez más, hacia un regimiento de plutócratas demagogos, y quizás, de tal modo, se encaminan hacia una transformación radical. Similar a una de aquellas que ya se observaron en el pasado (Pareto, 1964. pp. 691-692) ${ }^{20}$.

Lo que se puede señalar, finalmente, es que la dimensión política se encuentra en los momentos actuales en el centro del análisis y el debate sobre el problema de la corrupción. A ello, se suma, el protagonismo que ha adquirido en los últimos años como centro neurálgico el tema del desarrollo de la economía, a través de la flexibilización de los controles de los mercados internos y las cadenas globales de producción y consumo, como parte intrínseca de la primacía del relato que la vincula con el éxito económico dentro del imaginario colectivo. Esto va aunado a la incapacidad de redefinir la presencia de una democracia a la altura de las circunstancias y no una democracia de baja intensidad que lo permite todo, desde la misma corrupción hasta la propia impunidad. Me refiero a la discapacidad del sistema político para tratar la corrupción en toda su verdadera dimensión. Se realiza la implantación de una arquitectura contra la impunidad, en base a la creación y desarrollo de un llamado "Derecho Corporativo contra la Corrupción y la Impunidad"; es decir, una lex mercatoria que en el presente caso como lo señalamos, se sitúa por encima de los derechos humanos y de la naturaleza, y que cierra el círculo del poder, a favor de las grandes empresas desde el ámbito jurídico ${ }^{21}$, y que en el presente caso, aparece ubicada en el contexto propio de la corrupción.

\section{BIBLIOGRAFÍA}

- Hernández, J. (2012) "El casino que gobierna el mundo: mañas y trampas del capitalismo financiero". Ediciones Le monde diplomatique. «El Diplo» Capital intelectual, (c) de la presente edición: Capital Intelectual. S.A. Primera edición argentina: junio de 2012, p. 48.

- Miró, Llinares, Fernando (s.f) "La oportunidad criminal del ciberespacio. Aplicación y desarrollo de la teoría de las actividades cotidianas para la prevención del cibercrimen". http://criminet.urg. es/recpc.

- Fernández, G. (2016) "Alternativas al poder corporativo: 20 propuestas para una agenda de transición en disputa con las empresas trasnacionales". Icaria - Antrazyt. Economía, Barcelona.

- ROSE - ACKERMAN, S. (s.f.) "The political Economy of Corruption", en ELLIOT, KIMBERLY A.: "Corruption and the global Economy". Mencionado por DEMELSA BENITO SÁNCHEZ, en "EI Delito de corrupción en las transacciones comerciales internacionales".

- Fabián, E. (2003) "La corrupción del agente público extranjero e internacional”. Tirant lo Blanch, Valencia. Mencionado por DEMELSA BENITO SÁNCHEZ, en "EI Delito de corrupción en las transacciones comerciales internacionales". Ob. cit., p. 42.

- Rabotnikof, N. (1999) "Corrupción política: definiciones técnicas y sentidos sedimentados". Universidad Nacional Autónoma de México.

- Mantellini G., Pedro J., Aniyar, L. y Linares M. (agosto 1980) TEMA, III. "Delincuentes y abuso de poder: delitos y delincuentes fuera del alcance de la ley" p.43, VI Congreso De Las Naciones Unidas Sobre Prevención Del Delito Y Tratamiento Del Delincuente, Ilevado a cabo en Caracas, Venezuela.

\footnotetext{
Ibid. p. 78.
}

21 Hernández, J. y Ramiro, P. (2016) “Contra la 'lex mercatoria'. Propuestas y alternativas para desmantelar el poder de las empresas trasnacionales", Icaria, Barcelona. Mencionado por FERNÁNDEZ ORTIZ DE ZÁRATE, GONZALO. En "Alternativas al poder corporativo. 20 propuestas para una agenda de transición en disputa con las empresas trasnacionales". Icaria, Antrazyt. Economía, p. 45. 
- Mény, Y. (1995) "Política, corrupción y democracia”. En Política y Gobierno, Volumen III, Número 1. Primer semestre.

- Mayorca, J. (1977) "Criminalidad de la Burguesía". , Caracas.

- Sapelli Giulio (1998) “Cleptocracia. El 'mecanismo único' de la corrupción entre economía y política". Editorial Losada, Buenos Aires

- Pareto V. (1964) "Trattato di sociología generale". Introducción de N. BOBBIO, Comunitá, Milán, Copiado de SAPELLI GIULIO.

- Hernández, J. Y Ramiro, P. (2016) "Contra la 'lex mercatoria'. Propuestas y alternativas para desmantelar el poder de las empresas trasnacionales", Icaria, Barcelona. Mencionado por FERNÁNDEZ ORTIZ DE ZÁRATE, GONZALO En "Alternativas al poder corporativo. 20 propuestas para una agenda de transición en disputa con las empresas trasnacionales". Icaria, Antrazyt. Economía.

Fecha de recepción: 22 de mayo de 2020

Fecha de aceptación: 01 de junio de 2020 